\title{
Simulation-Based Service Process Benchmarking in Product-Service Ecosystems
}

\author{
Maik Herfurth ${ }^{1}$, Thomas Schuster ${ }^{2}$, and Peter Weiß ${ }^{3}$ \\ ${ }^{1}$ Hilti AG, Schaan, Liechtenstein \\ ${ }^{2}$ FZI Forschungszentrum Informatik, Karlsruhe, Germany \\ ${ }^{3}$ International Business School of Service Management, Hamburg, Germany \\ maik.herfurth@hilti.com, schuster@fzi.de, weiss@iss-hamburg.de
}

\begin{abstract}
Increasing market competition leads to a differentiation of service providers by offering hybrid services as value added services. In productservice ecosystems the effectiveness of cross-company business processes constitutes a major competitive factor. In this paper, we present a procedure model for simulation-based process benchmarking in the domain of industrial service procurement. In focus are cross-company business processes in service networks in bilateral collaboration scenarios of service providers and service consumers. A systematic analysis of performance indicators measures reveals weaknesses and potential for improvement. A set of hands on uses cases realizes validation and evaluation of yielded benchmarking results.
\end{abstract}

Keywords: service processes, service procurement, benchmarking, business process simulation.

\section{Introduction}

Current surveys highlight that services will constitute an integral element of many products creating value offerings to customers [1]. Industrial services being a part of product-service systems (PSS) gain importance. These value added services are delivered through external service providers granting availability and reliability of industrial facilities and infrastructures. Industrial services make a significant share of companies total spending and ensure required operational levels and availability of systems and facilities. For the procurement of industrial services, organizations consisting of service providers and service consumers interact in product-service ecosystems. The paper is focusing on how the collaboration and interaction of organizations can be measured and improved. Our presented research approach is based on case studies of a research and standardization project [2][3].

\section{Product-Service Ecosystems for Service Procurement}

Today digitalization is omnipresent and increases competition between companies. New developments in ICT (information and communication technologies) require 
companies to create new innovative value offerings for their customers combining products and services in order to sustain on the market. Hence, the ability to integrate and share products and services offerings of external business partners turns out to be a major competitive factor in future. In consequence, service suppliers take focus on supporting customer's processes or even offering to take offer whole or parts of its value creation processes (through outsourcing). Service suppliers and service consumers are collaborating in so-called industrial service networks. These networks are part of product-service ecosystems. In these service networks, the production of services is in focus. Since service consumers request different service types from different service suppliers, new ways of flexible collaborations are emerging. The internal and cross-company business processes describing the administrative processes for the procurement of services are called service processes. The collaborations are always confronted with similar challenges: The missing harmonization, integration and standardization of cross-company service processes. Therefore creation of new collaborations suffer from low quality of business interactions caused by integration and transaction costs, manual exception handling, offline communication (media breaks) and procurement times; also resulting in less transparency and low quality of processes and data. In focus of industrial service procurement is an integrated perspective of goods and services [4][5].

Service E-Procurement and E-Business-Standards. The use of e-business solutions supports strategic and operative procurement activities, resulting in lower costs and improved competitiveness. Service e-procurement constitutes an important segment of e-business activities. It compasses extensive use of ICT to improve productivity and business processes. Effective service procurement requires looking at distinct phases (encompassing planning, negotiation, delivery to payment). Respective automation of a business process, in whole or in part results in an electronic process. In electronic business documents, information or tasks are passed from one participant to another for action, according to a set of procedural rules [6]. Electronic processes support business interactions reducing interfaces, process and throughput times and support harmonization of meta data, activities, procedures and integration of resources. E-business standards support a shared process understanding and increase process transparency amongst business partners by harmonization and structuring of exchanged business data. In this way, e-business standards facilitate enhanced interoperability. For the domain of service e-procurement, various e-business standards do exist, however, do not adequately support service procurement operations, lacking appropriate business objects (documents, information) and required service logic of respective procedural rules and control flows.

Challenges. Business processes and respective exchange of documents and information lack harmonization. Business processes must support procedural rules and service logic of required business interactions and communication between service suppliers and requesters [4] [5]. Industrial service procurement is still source of high cost because underlying business processes are error prone. Errors and failures occur foremost through the absence of coherent e-business standards and reference frameworks offering meta models of processes, data objects and interaction patterns taking into account the service logic. Although, a variety of e-business standards and 
frameworks is available, they typically cover solely parts and phases of business processes, and are cause of numerous media breaks and inefficiencies such as manual error and exception handling, decreasing productivity of service operations. Due to these challenges, collaborations in service procurement networks seek for standardized, optimized and key performance indicator based service processes.

\section{Quantitative Evaluation of Service Processes}

To meet the challenges described above, a quantitative evaluation of service processes identifies further improvement opportunities. A quantitative analysis of service processes validates pre-defined service process targets based on best practices and leading companies. The result is the improvement of the efficiency (performance) and productivity of the business processes. The process efficiency does have several impacts, hereto especially the following improvements are of interest like the reduction of process costs, reduction of process times, reduction of process throughput time, the improvement of process quantity, improvement of process transparency and increase of process flexibility. Service processes of administrative order processing in productservice ecosystems in the domain of service procurement weren't drew much attention. These service processes need many resources, long process times and throughput times. Inefficiencies result from the internal and especially cross-company handling und coordination of transactions und non-harmonized and non-integrated electronic service processes.

Business Process Simulation. Business process simulation (BPS) [7][8][9] can used to support business process benchmarking and furthermore BPS can be seen as a part of business process improvement (BPI) [10]: the continuous progression of market competition by a continuous comparison of market competitions and adaption of business processes. In the domain of service procurement, different service process variants, internal and company-wide service processes in product-service ecosystems can be compared. The efficiency of service processes in service collaborations can be measured by defining different service process simulation models. Those simulation model variants of simulation models can be simulated. For the execution of simulation runs, relevant process inputs and process parameters have to be defined. Possible scenario variants are order volumes as process input or the amount of human resources. The execution of simulation experiments can be used to gain insights about a real system at build time [11]. The advantages of business process simulation experiments are [8][12][9]:

- Most real systems cannot be analyzed by analytical methods

- Simulation models allow for analysis in different environments and under different conditions and lower risks and can easily be changed and adapted

- The behavior of business processes can be analyzed on a much broader scale and alternative developments can be syntactically and semantically analyzed and visualized

- Simulation experiments are repeatable and can be designed easily and executed in a cost-efficient way 
- Systems can be simulated in very short or very long time periods. A simulation experiment takes less time than real experiments and no experiments are executed on real systems so they are not endangered

- Different action alternatives and scenarios can be simulated to gain important statement prospectively

Business Process Benchmarking. Camp [3] defines benchmarking as "the search for solutions, based on the best methods and procedures of the industry, the best practices, to lead a company to top performance". Benchmarking is a method to compare products, services and business processes. A systematic analysis of performance differences and their cause helps to detect possible improvement potentials. Benchmarking is a continuous process to compare business processes across different companies. Therefore differences and causes as well as possibilities for further improvements will be detected. Target dimensions of benchmarking are quality, costs and times and customer orientation. Types of benchmarking of companies are internal and external benchmarking. An internal benchmarking is company-related (internal benchmarking). An external benchmarking is marketrelated (competitive benchmarking of best practices) [13]. The process benchmarking serves as an instrument to expose existing deficits like productivity and performance gaps, lacking process transparency and lacking link between strategic and operative targets. The analysis of service processes serves as identification and provision of mission critical data for a performance comparison to identify potentials for improvement. In the domain of service procurement inefficiencies of service processes result from sequential process flows, multistage processes, poor data quality of information flows, insufficient customer-supplier-orientation, poor information transparency and non-value creating activities. In product-service ecosystems in the domain of service procurement, service customers and service supplier are benchmarking partners. Different combinations of service customers and service supplier can be benchmarked pairwise to compare and improve the business process performance.

\section{Procedure Model for Simulation-based Service Process Benchmarking}

For the execution of simulation-based service process benchmarking, a procedure model in dependence on Neumann [7], Schuster [12] and Wildemann [14] is presented. The procedure model defines a structured approach for the quantitative evaluation of service processes. In order to meet the requirements in line with business process benchmarking, an adequately structured procedure model needs to be defined. The described approach extends and details a phase oriented procedure model for the analysis, modeling, simulation and benchmarking of business processes in productservice ecosystems. The procedure model combines the advantages of business process simulation and business process benchmarking in a common approach. Bilateral collaborations of service consumers and service suppliers can be benchmarked. In Fig. 1, the procedure model is shown with its cyclic different phases. 

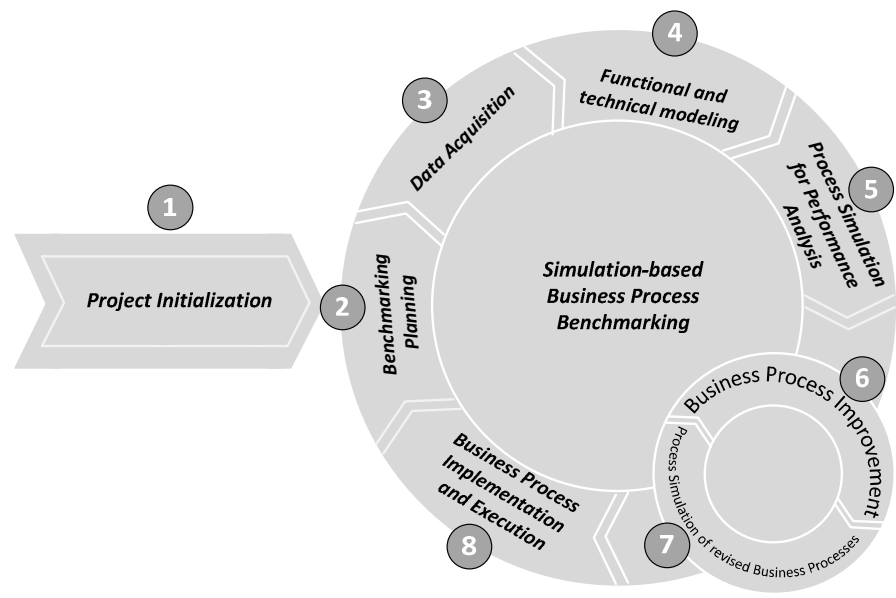

Fig. 1. Simulation-based business process benchmarking procedure model

Project Phases. The procedure model consists out of eight process phases:

1. Project Initialization: The organizational determining factors are defined. The fundamental target of the project and the project scope as well as the involved people and organization units are defined. Data and information suppliers are defined and the project specific framework like resources, budget and timeline are determined. Based on strategic planning, targets are refined to derive tactical and operational targets.

2. Benchmarking Planning: The target definitions of service processes have to be reviewed continuously. In the benchmarking planning phase, benchmarking targets are defined. Benchmarking objects are defined like the analysis area, the choice of structured business process models, needed resources, benchmarking-partners, key performance indicators and methods. Conditions are defined for the execution of benchmarks with the benchmarking partners. For the modeling and simulation of business processes, a modeling language and a modeling and simulation tool has to be chosen.

3. Data Acquisition: Process inputs and process outputs of the business processes are defined. The existing process flows are analyzed and comparative data of potential benchmarking partners are collected. Secondary data sources are also used.

4. Functional and Technical Modeling: Technical framework requirements are defined for the technical modeling. Requirements for resources are determined. During the functional modeling, service processes and service objects are modeled. In the context of a hierarchical process modeling, service processes are modeled on different abstraction layers. During a successive refinement, service processes are modeled on a high modeling layer and complex activities are consecutively refined. Hierarchical service process models combined with a modularization of service processes support the decomposition and application of service processes. 
5. Process Simulation for Performance Analysis: For the business process evaluation, key performance indicators are selected and defined. Critical factors and main influence factors are specified. The service processes are simulated. Based on the simulation evaluation of service processes, possible patterns can be identified. The simulation of service processes is executed for a longer time period. After the simulation, the simulation model has to be verified and validated. For the verification, the transformation of the process model into a simulation model is analyzed. For the validation, the reproduction fidelity of the process model and the fidelity of the simulation parameters based on the simulation results are analyzed.

6. Process Improvement: Targets of process improvements are defined and possible process alternatives are generated. Based on alternative process flows, improved process structures can be identified and realized. The process model is configured with alternative parameters in order to enable a comparison between different configurations und their implications on the process model.

7. Process Simulation of Revised Business Processes: Improved service process models or different service process model variants are simulated. The phases of process improvement and process simulation of improved business process are iterative: improved process models and variants can be simulated until the target definitions are met. The process simulation of the revised business processes ends with the preparation of the simulation results.

8. Business Process Implementation and Execution: The improved service process models can be implemented to operate a business. Change management has to be executed for practical training and mind change of personal resources.

\section{Evaluation of the Procedure Model}

The procedure model for simulation-based service process benchmarking serves as an approach to strengthen the competition position of a company. Business process simulation complements business process benchmarking and serves as an adequate method. The advantages of business process simulation increase the value of process benchmarking. The execution of a process benchmarking identifies differences of relevant factors like throughput times, resource assignments or cost items. The causes of performance gaps can be analyzed. Based on benchmarks, performance gaps can be quantified. Redundant service processes and non-value creating activities can be identified. Possible automation potentials for service processes can be identified and the error data is reduced. Also the cost-effectiveness of service processes can be ensured. Problems of the simulation-based service process benchmarking evolve due the comparability of service processes and the effort for the information search of competitive company data. However, the information retrieval of other companies can be difficult as a result of losing competitive advantages. For the simulation models, a realistic model calibration has to be found. The identification of benchmarking objects, the modeling of service processes and process evaluation acquires some effort. 
Benchmarking of Service Processes in bilateral Service Procurement Networks. The method of simulation-based service process benchmarking has been successfully applied in a research projects in the domain of service procurement [4]. The service process models of 18 use cases between six service suppliers and four service customers were analyzed, modeled, simulated and benchmarked. The evaluated uses cases were compared pairwise for benchmarking applying the presented procedure model. Service process models were modeled with service nets [15], a higher petri net variant of XML nets. The modeling of service nets was based on a reference process model to structure and align the individual service processes. For the modeling and simulation of service process models, the software tool Horus [6] was used for a software based simulation. As key performance indicators for obtaining relevant conclusions about the efficiency and performance of the analyzed service process models, we were concentrating on the process time, the process throughput time, used human resources and media breaks. For the benchmarking of several service procurement use cases in bilateral collaboration scenarios, historical data from real business process evaluations were used to calibrate the simulation process models [5]. As process input, the data amount of service orders per day, the time period of a year, the average amount of resources, the amount of failure checks and repeating activities like double work and the process and process throughput times were taken. As business process simulation method, a discrete event driven business process oriented simulation was used [9]. The strengths of this approach are the independent simulative analysis of the real system and the possibility of a "playground" by simulating different process alternatives. Evaluation of simulation results can shed light on correlations of system parameters at build time and can be used to develop action strategies [7]. Therefore alternative resource configurations in business processes and their allocations can be simulated and possible impacts on process times and process throughput times at run time can be identified. Unlike analytical procedures, the simulation can be used for the analysis of large systems. Weaknesses are the abstraction of the simulation models since with an increasing abstraction level, the granularity of model descriptions of the real system decreases. Also the dependency of data input for the benchmarking approach can be an obstacle. As a main implication of our analysis results, we can state that the benchmarking approach based on process simulation can serve as an adequate analysis method for a long-term process evaluation. Limitations exist due to the characteristics of the simulation and the derivation of the appropriate conclusions and measures.

\section{Conclusions and Outlook}

In this paper, a procedure model for the simulation-based service process benchmarking was presented. The procedure model offers an adequate proposition of an efficient way for the quantitative evaluation of service processes for benchmarking of bilateral collaborations in product-service ecosystems. The procedure model combines two efficient approaches for the quantitative evaluation of business processes: business process simulation and business process benchmarking. The integration of business process simulation for benchmarking allows for cost and effort efficient way to 
analyze and improve service processes in product-service ecosystems. This approach was evaluated from real-life case studies [5]. Next steps foresee to elaborate further detailed steps for this approach. Further benchmarkings of business process models in different domains are planned.

\section{References}

1. Federal Ministry of Economics and Technology: Industrial Services (2012), http: / / www. bmwi.de/DE/Themen/Industrie/IndustrienationDeutschland/industrienahe-dienstleistungen.html

2. Smeltzer, L.R., Ogden, J.A.: Purchasing Professionals' Perceived Differences between Purchasing materials and Purchasing Services. Journal of Supply chain Management 38(19), 54-70 (2002)

3. Camp, R.C.: Benchmarking. München/Wien (1994)

4. eBusInstand - Einsatz von Standards in der industriellen Instandhaltung, research and standardization project funded by Federal Ministry of Economics and Technology (2011), http: / / www . ebusinstand. de

5. Weiß, P., Herfurth, M., Schumacher, J.: Leverage Productivity Potentials in Serviceoriented Procurement Transactions: E-Standards in Service Procurement. In: Proceedings of RESER 2011 (2011)

6. Schönthaler, F., Vossen, G., Oberweis, A., Karle, T.: Business Processes for Business Communities - Modeling Languages, Methods, Tools. Springer (2012)

7. Neumann, S.T., Rosemann, M., Schwegmann, A.: Simulation von Geschäftsprozessen. In: Becker, J., Kugeler, M., Rosemann, M. (eds.) Prozessmanagement: Ein Leitfanden zur Prozessorientierten Organisationsgestaltung, pp. 437-456. Springer (2002)

8. von Haaren, B.: Konzeption, Modellierung und Simulation eines Supply-ChainRisikomanagements. Dissertation University of Dortmund (2008)

9. Banks, J., Carson, J.S., Nelson, B.L., Nicol, D.M.: Discrete-Event System Simulation. Pearson Education (2005)

10. van der Aalst, W., van Hee, K.: Workflow Management: Models, Methods, and Systems. MIT Press (2002)

11. Page, B., Kreutzer, W.: The Java Simulation Handbook: Simulating Discrete Event Systems with UML and Java. Shaker Verlag (2005)

12. Schuster, T.: Modellierung, Integration und Analyse von Ressourcen in Geschäftsprozessen, Dissertation. KIT Scientific Publishing (2012)

13. Bodmer, C.: Benchmarking im Einkauf. In: Boutellier, R., Wanger, S., Wehrli, H. (eds.) Handbuch Beschaffung. Hanser Verlag (2003)

14. Wildemann, H.: Prozess-Benchmarking - Leitfaden zur Erreichung von Quantensprüngen in Geschäftsprozessen. TCW (2012)

15. Herfurth, M., Schuster, T., Weiß, P.: Simulationsbasierte Analyse von Lösungskonzepten im Service E-Procurement. In: Mattfeld, D.C., Robra-Bissantz, S. (eds.) Proceedings Informationssysteme in der Dienstleistung: Service Engineering \& Management, Multikonferenz Wirtschaftsinformatik MKWI 2012 (2012) 